\title{
Los nuevos distritos creativos de la Ciudad de Buenos Aires: la conversión del barrio de La Boca en el "Distrito de las Artes"
}

Ana Gretel Thomasz. Universidad de Buenos Aires, Buenos Aires, Argentina.

RESUMEN | La sectorización de la ciudad de Buenos Aires en una serie de distritos "creativos" es una innovación introducida por la gestión de gobierno que conduce la urbe desde 2008. Abreva en el modelo de ciudad creativa propuesto por Florida $(2002 ; 2005)$ y se funda en una peculiar modalidad de intervención pública en la cual el Estado actúa como facilitador del mercado, otorgando beneficios económicos a los inversores interesados en radicarse en los nuevos distritos. La institucionalización de tal política -deudora del urbanismo liberal- ha suscitado movilizaciones vecinales en las áreas afectadas. El caso que aquí se examina es la creación, en 2012, del Distrito de las Artes en el barrio de La Boca. Resulta relevante examinar la disposición tras esa acción estatal atendiendo a los posicionamientos de los vecinos. En esta perspectiva, dado que el trabajo etnográfico realizado indica que la intervención en La Boca lesiona diversos derechos consagrados en la Carta Mundial por el Derecho a la Ciudad, para efectuar el presente análisis se recurre a dicho documento.

PALABRAS CLAVE | política urbana, conflicto social, vivienda.

ABSTRACT | The segmentation of the city of Buenos Aires in several "creative" districts is an innovation introduced by the government administrating the city since 2008. That segmentation is inspired by the creative city model proposed by Florida $(2002,2005)$ and is based on a particular way of public intervention in which the state acts as a market facilitator, providing economic benefits to the investors interested in settling in the new district. The institutionalization of such policy-inspired by the liberal urbanism-generated neighbor's demonstrations in the affected areas. In 2012 the Art District was created in La Boca neighborhood. It seems relevant to explore such intervention taking into account the neighbors' positions, as the ethnographic work developed indicates that this situation weakens several rights contained in the World Charter for the Right to the City, referred hereby for the analysis carried out.

KEY WORDS | urban policy, social conflict, housing.

Recibido el 12 de mayo de 2014, aprobado el 13 de marzo de 2015

E-mail: gretel2007@gmail.com 


\section{Introducción}

La sectorización de la ciudad de Buenos Aires en una serie de distritos o clústeres "creativos" es una innovación introducida por la gestión de gobierno que conduce la ciudad desde 2008. Actualmente, la urbe cuenta con cuatro distritos: el Distrito Tecnológico, el Distrito del Diseńo, el Distrito de las Artes y el Distrito Audiovisual. A diferencia de este último, que se emplaza en la zona norte, los otros tres se localizan en el sector sur de la ciudad. La conversión de antiguos mercados o establecimientos industriales en megacentros temáticos, la convocatoria al sector privado, la habilitación de una serie de incentivos económicos y-como se verá- el virtual desconocimiento de los intereses de los ciudadanos que residen en los espacios urbanos afectados, son los denominadores comunes que subyacen a la política de creación de distritos.

Esa política abreva, por otra parte, en el modelo de ciudad creativa propuesto por Florida $(2002 ; 2005)$, pues propicia la clusterización o concentración geográfica de las industrias creativas, bajo el supuesto de que la contigüidad física -o la aglomeración de agentes, firmas e instituciones en espacios que reúnen ciertas característicasresulta positiva en términos urbanos y económico-productivos.

Son múltiples las críticas que recibió la noción de clúster y el modelo formulado por Florida, y su supuesta capacidad para optimizar la productividad y promover el desarrollo urbano (Amin \& Cohendet, 2004; Martin \& Sunley, 2003; Pacheco Vega, 2007). La escasa atención prestada a las conexiones globales "en la constitución de lo local" (Tironi, 2010, p. 164) es un punto débil de dicho modelo (Grabher, 2001; Slater \& Ariztía, 2009).

El propósito de este artículo no es, sin embargo, someter a crítica las nociones de clúster o de ciudad creativa, sino examinar cómo la creación de los distritos afecta a la población que habita en los espacios así delimitados por el poder político.

La primera parte del trabajo examina en términos generales la política de clusterización de las industrias creativas implementada en la ciudad de Buenos Aires. La segunda parte, en cambio, concentra la mirada en el barrio de La Boca. Atiende a los posicionamientos de los ciudadanos que habitan en el área relativos a la conversión de "su" espacio urbano en un nuevo distrito, el Distrito de las Artes, y recupera sus voces. A tal efecto, retoma el trabajo etnográfico efectuado durante 2012 en los diversos encuentros e instancias en las que vecinos, artistas, maestros, trabajadores de la salud, trabajadores sociales y miembros de organizaciones sociales, culturales y políticas boquenses discutieron el proyecto de ley que planificaba convertir la zona en un nuevo distrito "creativo". Dicha labor etnográfica se basó en el uso de técnicas cualitativas y herramientas metodológicas convencionales, tales como el desarrollo de actividades de observación participante en los encuentros referidos, la toma de notas de campo de primera mano en esos contextos y, en algunos casos, la elaboración de un registro de tipo magnetofónico. Esos materiales se complementaron luego (durante 2013) con las conversaciones informales y charlas que se mantuvieron con algunos vecinos, y con las múltiples entrevistas abiertas que se realizaron a artistas, trabajadores y militantes boquenses. Se recopilaron asimismo fuentes 
secundarias (periódicos barriales, volantes de organizaciones sociales, programas radiales, y otros) y documentos oficiales relativos al Distrito de las Artes ${ }^{1}$.

\section{Los nuevos distritos}

El Distrito Tecnológico (DT) fue creado en 2008 a través de la Ley No 2972. Afecta parcialmente los barrios de Boedo, Parque de los Patricios y Pompeya, sumando 200 hectáreas. Brinda una serie de desgravaciones impositivas a empresarios o inversores del campo de las telecomunicaciones y las nuevas tecnologías de la información dedicadas a la producción de software o hardware que estén interesados en radicarse en el área delimitada como distrito. La exención del impuesto que grava la compra de inmuebles (Impuesto de Sellos); del que grava el ejercicio de actividades profesionales, comerciales y lucrativas (Ingresos Brutos); y de la contribución que deben efectuar los propietarios o locatarios de inmuebles por el servicio de alumbrado, barrido y limpieza de las calles de la ciudad que brinda el sector público -llamado Impuesto Inmobiliario Alumbrado, Barrido y Limpieza, más conocido por la sigla ABL-, son algunas de las facilidades que brinda la norma.

Ya se han establecido en el área más de 160 empresas. Actualmente, el Gobierno de la Ciudad de Buenos Aires se encuentra acondicionando un viejo edificio local para convertirlo en un espacio que albergue oficinas, comercios y sedes de instituciones vinculadas a las telecomunicaciones, llamado Centro Metropolitano de Tecnología.

Creado en 2011 mediante la aprobación de la Ley No 3876, el Distrito Audiovisual (DAv) ocupa una superficie de 559 hectáreas. Involucra los barrios de Chacarita, Villa Ortúzar y Paternal, y sectores de Colegiales y Palermo. Es su propósito promover la industria audiovisual estimulando el establecimiento de empresas y productoras de cine, televisión, publicidad y animación, a las que se les extienden exenciones impositivas similares a las que rigen en el Distrito Tecnológico. Un viejo mercado de la zona en el que operan oficinas y dependencias públicas involucradas con la implementación de la norma, fue reconvertido en la sede oficial de la nueva jurisdicción.

El Distrito del Diseño (DD) ocupa 230 hectáreas del barrio de Barracas. Aunque la normativa que le dio fuerza de ley a la iniciativa se aprobó en diciembre de 2013, el Gobierno de la Ciudad de Buenos Aires presenta al área como DD desde 2005, momento en el que inauguró el Centro Metropolitano del Diseño (cMD) en un antiguo edificio en el que funcionó el Mercado del Pescado de Barracas. Allí se realiza anualmente el Festival Internacional del Diseño. El CMD se presenta como el faro del distrito, que favorece en este caso la radicación de empresas y profesionales del campo del diseño gráfico, textil, de indumentaria e industrial, a quienes se les ofrecen los mismos beneficios fiscales que en los casos anteriores.

1 Si bien este artículo recoge el trabajo de investigación desarrollado durante 2012 y 2013 , dicho trabajo se prolongó en 2014 y continúa en curso actualmente. Se encamina a documentar los cambios producidos en La Boca en virtud de la reglamentación y puesta en vigencia de la ley que lo convirtió en Distrito de las Artes. 
La Ley No 4353, aprobada a fines de 2012, creó el Distrito de las Artes (DA) en el barrio de La Boca y sectores de San Telmo y Barracas ${ }^{2}$. Comprende 300 hectáreas aproximadamente. La conversión de una vieja y desactivada usina eléctrica boquense en un imponente y selecto espacio cultural que recibió el nombre de "Usina de las Artes" y se inauguró en mayo de 2012, fue el acontecimiento urbano que precedió a la creación de este distrito.

\section{Figura 1 | Plano del Distrito de las Artes}

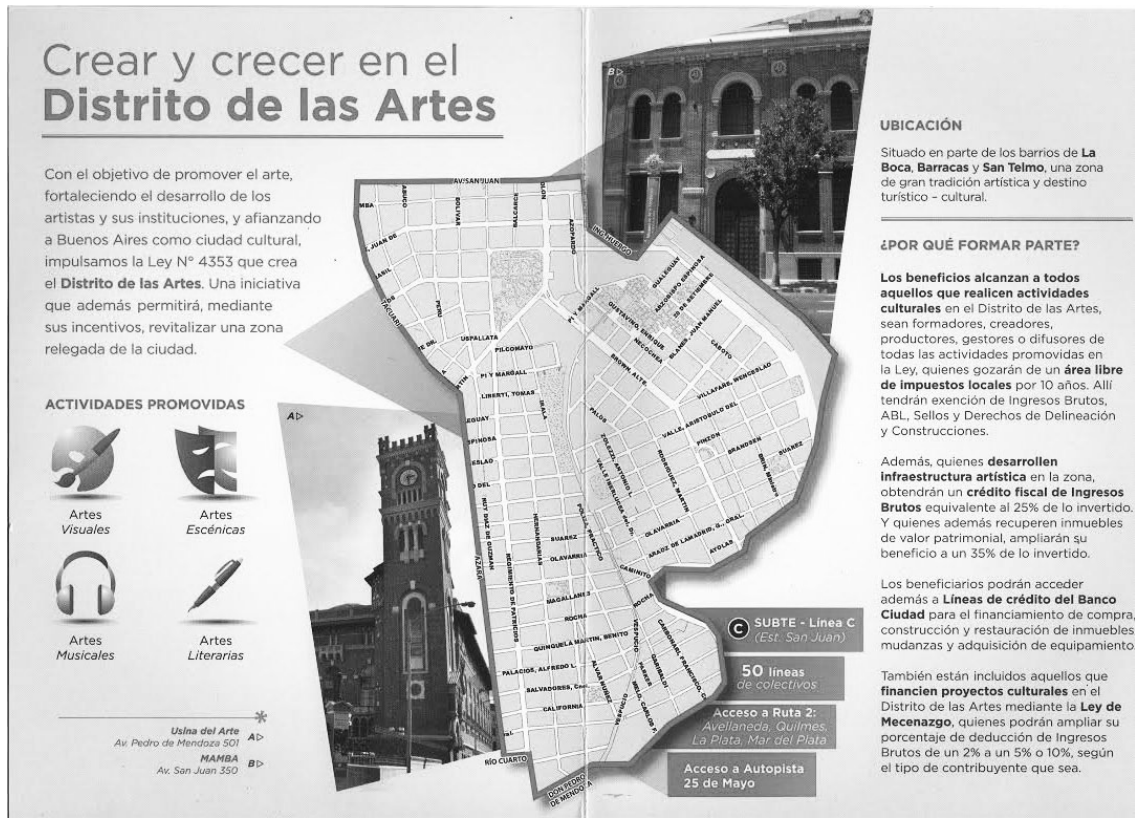

FUENTE GOBIERNO DE LA CIUDAD DE BUENOS AIRES

Las otras tres figuras merecen algunos comentarios. La primera, que reza "quienes realicen en forma principal alguna de las actividades promovidas", indica a los potenciales beneficiarios que deben destinar al desarrollo de las actividades artísticas fomentadas por la ley el $50 \%$ de la superficie del inmueble que ocupan, o de la facturación que generan, de la cantidad de empleados que poseen y/o de la masa salarial involucrada. La figura interpela así a los artistas independientes que desenvuelvan actividades creativas en espacios o talleres montados a tal fin o bien en los inmuebles en los que residen (siempre y cuando afecten el $50 \%$ de esos inmuebles al ejercicio de tales actividades). Pero, en segunda instancia, convoca también a otras personas que, sin ser artistas ni considerarse como tales, se dediquen en un $50 \%$ a gestionar, comercializar o difundir obras o productos artísticos realizados por terceros. Ciertamente, la letra de la Ley No 4353/12 funde y con-funde en una

2 Los límites del distrito son la avenida Regimiento de Patricios, Río Cuarto, Martín García, Tacuarí, avenida San Juan, avenida Ingeniero Huergo, avenida Elvira Rawson de Dellepiane, la Dársena Sur y la ribera norte del Riachuelo. 
misma frase al artista -al creador o "productor" de obras artísticas, en la terminología que se utiliza allí- con otro tipo de agentes que mercantilizan, comercializan o difunden "obras artísticas". La ambigüedad es muy notoria, puesto que ni la ley ni la reglamentación aclaran tampoco qué se entiende por "obra artística". Ambas se limitan a expresar que se promueve la creación, producción, gestión, comercialización y difusión de obras artísticas vinculadas a las artes visuales, musicales, literarias y escénicas. De resultas, dentro de la figura difusión o gestión de "obras artísticas" pueden incluirse tanto artistas independientes como galeristas, empresarios o grandes corporaciones dedicadas a comercializar o difundir productos vinculados a las industrias culturales, tales como discos, películas, libros u otro tipo de mercancías "artísticas". Podrían incluirse, además, locales -comerciales o no- que exhiban "obras artísticas" en un "50\%”, y que destinen el 50\% restante a otros fines (restaurante, bar, oficina, residencia u otros).

\section{FIgURA 2 Usina de las Artes}

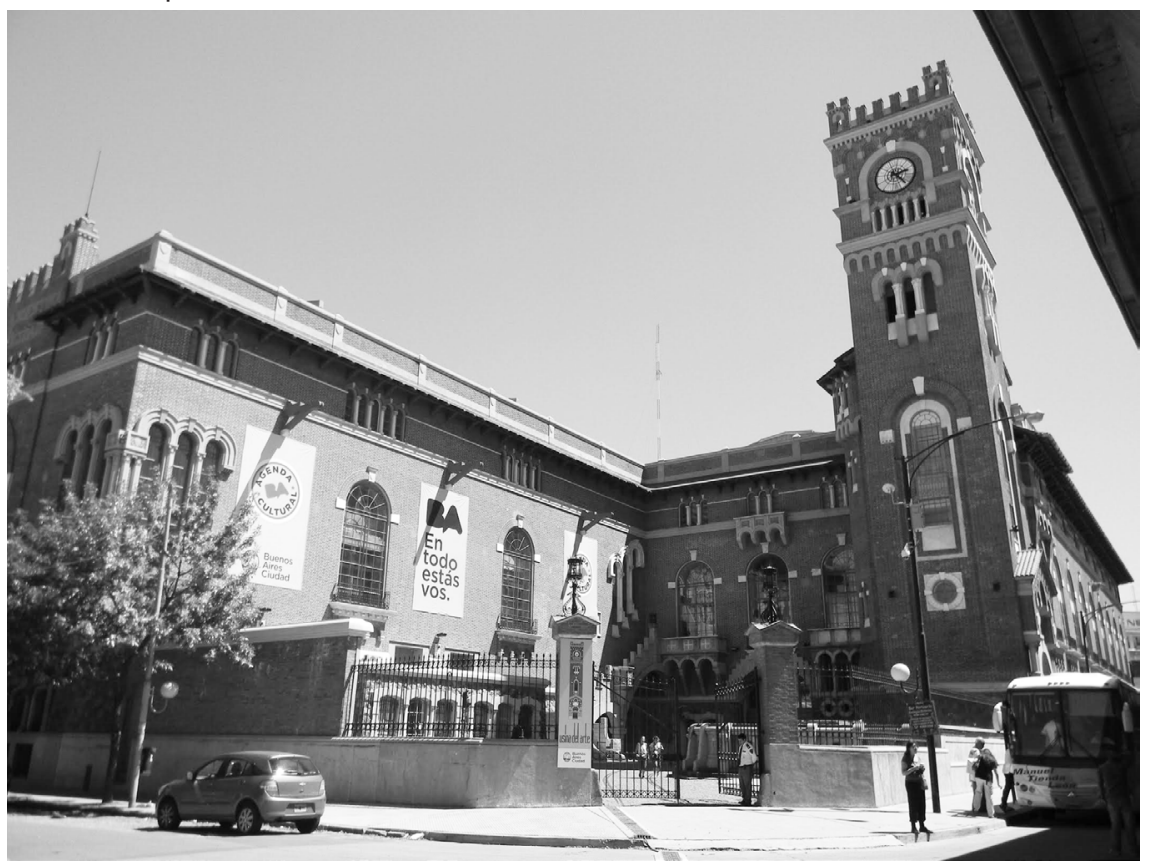

FUENTE FOTOGRAFÍA DE LA AUTORA

El Distrito de las Artes promueve la creación, producción, gestión, comercialización y difusión de obras artísticas vinculadas a las artes visuales, musicales, literarias y escénicas. Alcanza a personas físicas o jurídicas radicadas o que se radiquen en el Distrito de las Artes, contemplando distintos tipos de beneficiarios: "quienes realicen en forma principal alguna de las actividades promovidas", "desarrolladores de infraestructura artística", "Estudios de Artistas", "Centros Culturales" y "Centros Educativos". 
Los dos últimos tipos de beneficiarios (Centros Culturales y Centros Educativos) no requieren de mayores aclaraciones. Aluden, simplemente, a instituciones localizadas en el nuevo distrito que dicten cursos, talleres o carreras vinculadas a las actividades artísticas promovidas (esto es, las artes visuales, musicales, literarias y escénicas).

La segunda figura, titulada "desarrolladores de infraestructura artística", es definida así en el Artículo Cuarto de la disposición: "quienes realicen inversiones a través de la compra o locación de inmuebles para el fomento de las actividades promovidas"; "realicen ampliaciones y/o refacciones en inmuebles propios o alquilados", o "efectúen aportes para la compra, locación, ampliación o refacción de inmuebles" a fin de fomentar las actividades promovidas.

La denominación de la tercera figura, "Estudios de Artistas", resulta muy engańosa. No alude a titulares o locatarios de talleres artísticos, sino a propietarios o locatarios de edificios residenciales o espacios que se encuentren en un $30 \%$ ocupados por beneficiarios encuadrados en la primera figura legal mencionada, la titulada "quienes realicen en forma principal alguna de las actividades promovidas".

Los "incentivos económicos" que se otorgan a los beneficiarios consisten en exenciones impositivas similares a las que se habilitaron en los otros distritos: los ingresos económicos que se generen por ejercer las actividades artísticas promovidas quedan exentos del pago de Ingresos Brutos por diez ańos, y los propietarios de los inmuebles involucrados, del pago del Impuesto Inmobiliario ABL por un período semejante. Además, los beneficiarios que adquieran una propiedad en el Distrito de las Artes (los Desarrolladores de Infraestructura Artística) están eximidos de pagar el Impuesto de Sellos que grava la compra de inmuebles, y aquellos que construyan o refaccionen quedan eximidos de pagar la tasa de Derecho de Delineación y Construcciones. A todos los beneficiarios, por último, se les ofrecen créditos del Banco Ciudad para adquirir inmuebles, construir, efectuar mudanzas y/o adquirir equipamiento.

Resta señalar que el Ministerio de Desarrollo Económico es la autoridad de aplicación de las leyes que originaron los distritos y que los regulan. En lo que sigue se explora qué propósitos subyacen a la política de creación de distritos, al margen de sus finalidades inmediatas ya mencionadas: promover la industria tecnológica, audiovisual, del diseño y de las artes.

\section{Crecimiento y desarrollo}

Crecimiento, desarrollo, progreso, cambio, oportunidad, revitalización, regeneración, inversión, puesta en valor y recuperación son los términos que más se invocan en los documentos relativos a los distritos y que más circulan en los discursos de los funcionarios involucrados en su implementación.

La familiaridad y el sobreuso de esa terminología disuaden de formular interrogantes muy sencillos, tales como ¿qué tipo de crecimiento y desarrollo se pretende impulsar?, ¿se corresponden ambos con los requerimientos de los ciudadanos que habitan en los barrios afectados?, ¿obedece la creación de los distritos a la preocupación por fomentar el desarrollo social?, ¿puede la conformación de los distritos per se 
producir la revitalización de los espacios urbanos en cuestión?, ¿`se encontraban esos espacios efectivamente deprimidos o degradados?

En primera instancia, es posible afirmar que -en sintonía con el paradigma de la ciudad creativa y las teorías de los clústeres- impulsar la innovación, el crecimiento económico y el desarrollo urbano son los propósitos que rigieron la conformación de los distritos. Respecto de los beneficiarios del crecimiento económico, retomando a Florida $(2002 ; 2005)$ puede sostenerse que, al menos en teoría, serán los representantes de la nueva "clase creativa". Como lo explica Tironi (2010, pp. 164-165), la nueva clase creativa corresponde al grupo ocupacional que produce o agrega valor a través de su creatividad y que, según Florida, se ha convertido en el motor de la nueva economía posindustrial, a expensas del sector terciario. Añade Tironi (p. 165) que dicha clase comparte los atributos característicos de la llamada nueva clase media que fueron identificados por diversos autores (Du Gay, 1998; Du Gay \& Pryke, 2002; Featherstone, 1991; Jackson \& Thrift, 1995), tales como individualismo, alta capacidad de consumo, ansias de distinción cultural, alta movilidad y debilidad por la novedad y lo auténtico.

Sin negar que algunos integrantes de la nueva clase creativa puedan acogerse a los beneficios que ofrecen los distritos, resulta elocuente que, en la práctica concreta, quienes recogerán los principales réditos del crecimiento económico no serán necesariamente ellos, sino los empresarios privados que comercialicen o "gestionen" "obras artísticas" y que dispongan del capital suficiente para invertir y radicarse en dichos espacios. Ello dado que las leyes que regulan los distritos no brindan ningún tipo de beneficio fiscal a los vecinos que ya residen en los espacios urbanos afectados, salvo en el caso de que ya desarrollen actividades económicas vinculadas con los campos correspondientes a cada distrito (las telecomunicaciones, la industria audiovisual, el diseńo o las artes) y de que puedan acreditarlo ante los organismos públicos calificados.

De resultas, no serán los vecinos que habitan en los espacios urbanos afectados en general quienes se beneficien del crecimiento económico que -según el discurso oficial-generarán los distritos, sino los grandes inversores y emprendedores externos y, llegado el caso, la pequeña elite conformada por los elementos de la clase creativa. Efectivamente, en términos comparativos, las facilidades económicas que extienden los distritos resultan más redituables para los grandes inversores que posean capital suficiente ya sea para realizar operaciones inmobiliarias de compra de inmuebles, o bien para construir o refaccionar propiedades. Pues además de quedar excluidos del Impuesto Inmobiliario ABL, están librados de pagar los impuestos asociados a la compra, construcción o refacción de inmuebles (Impuesto de Sellos y Tasa de Delineación y Construcciones) y del pago de Ingresos Brutos. Mientras que el resto de los beneficiarios que no realicen operaciones inmobiliarias de esa índole solo gozan de la exención del ABL (y, como se verá luego, solo en algunos casos muy específicos, del pago de Ingresos Brutos).

En consecuencia, en términos de políticas públicas, los distritos no son otra cosa que convocatorias del Estado al sector privado para que se interese por los espacios urbanos convertidos en distritos, invierta y adquiera propiedades allí, radicando sus actividades económicas en esos lugares. La política en que se funda su creación 
parte, entonces, de la premisa de que solo el sector privado -más exactamente, la llegada y el establecimiento de empresarios e inversores- puede motorizar el crecimiento económico y el desarrollo urbano de dichos espacios (Espacio Chico Mendes, 2013, p. 21).

No obstante, es interesante notar que la creación de los distritos fue precedida o acompańada de ciertas acciones públicas tendientes a poner en valor esos espacios y a mejorar su infraestructura (incremento del transporte público y la iluminación, apertura de nuevas oficinas públicas, puesta en valor de plazas y parques, ampliación de veredas, plantación de árboles, colocación de plazoletas en avenidas). Esas intervenciones constituyen un reconocimiento indirecto de que la creación de los distritos per se no resulta suficiente para promover el desarrollo urbano de tales espacios. Parecen sugerir más bien que la actual gestión de gobierno parte de la premisa de que la principal función del Estado es actuar como facilitador del mercado, generando las condiciones para atraer al sector privado, y de que la llegada de inversores privados podrá, a posteriori, traccionar tanto el crecimiento económico como el desarrollo urbano de los espacios involucrados.

Y aquí cabe preguntarse nuevamente: ¿se corresponde el desarrollo urbano promovido con las necesidades de los ciudadanos que habitan en esos espacios?; la revitalización de los espacios reconvertidos por el poder en distritos, ¿favorece a los ciudadanos que habitan allí?

En lo que resta se intenta responder a esas inquietudes, focalizando la atención en el barrio de La Boca.

\section{FIGURA 3 | Folleto oficial del Distrito de las Artes}

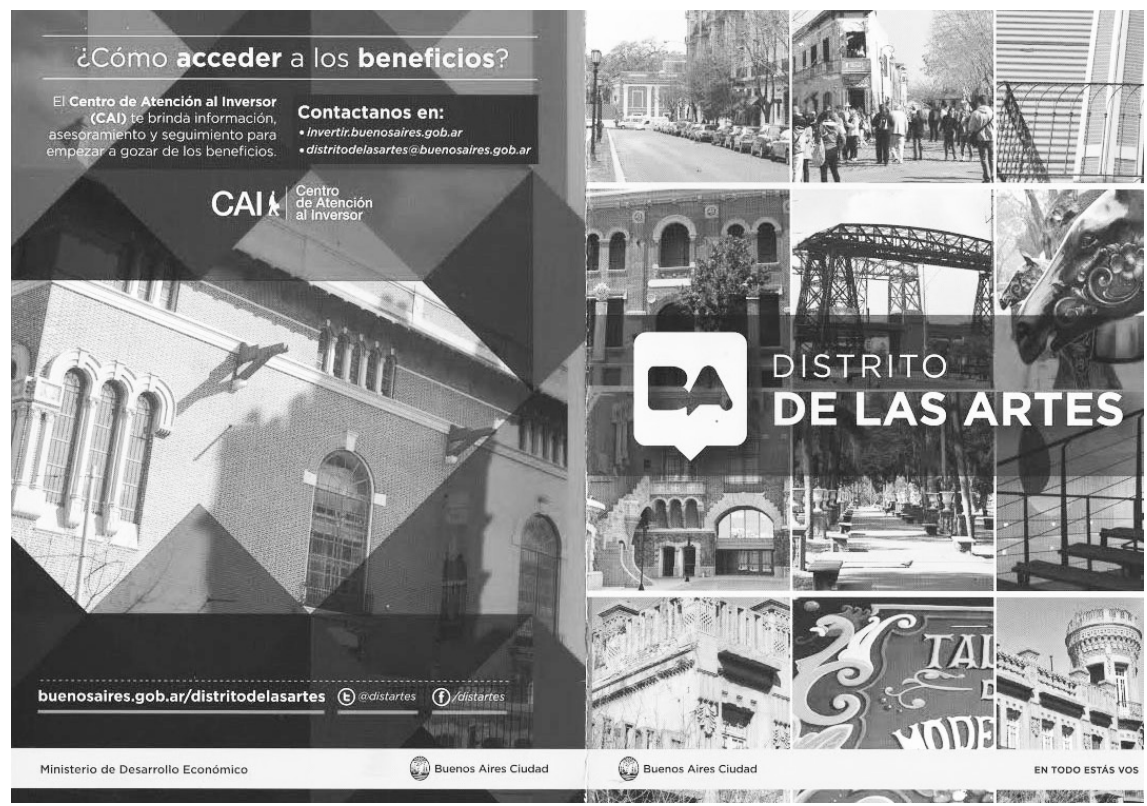

FUENTE MINISTERIO DE DESARROLLO ECONÓMICO, GOBIERNO DE LA CIUDAD DE BUENOS AIRES 


\section{El barrio de La Boca y la trastienda del Distrito de las Artes}

\section{Sectores populares y artistas}

Periférico, pobre y anarquista, La Boca era único con sus casas de chapa
pintadas de colores brillantes, rezagos de la pintura de los barcos, y el
movimiento constante de trabajadores cruzando el Riachuelo, de la ribera
a la Isla Maciel en el imponente transbordador inaugurado en 1914. (Iparraguirre, 2001, p.10).

El barrio de La Boca se ubica en el sector sur de la ciudad de Buenos Aires, junto a la ribera del Riachuelo, por donde limita directamente con la Isla Maciel (partido de Avellaneda, provincia de Buenos Aires). Se caracteriza por estar físicamente cerca pero simbólicamente lejos del centro de la ciudad. Las actividades portuarias e industriales que proliferaron en torno al río lo perfilaron históricamente como un barrio eminentemente proletario, como lugar de residencia de trabajadores y sectores populares. La precariedad y deficiencia de sus servicios públicos e infraestructura (pavimentación, iluminación, redes de gas, agua, y otras) y la abundancia de casas de inquilinato de chapa acanalada, madera y hierro conocidas como conventillos, son algunos rasgos distintivos del lugar (Thomasz, 2014, p. 94).

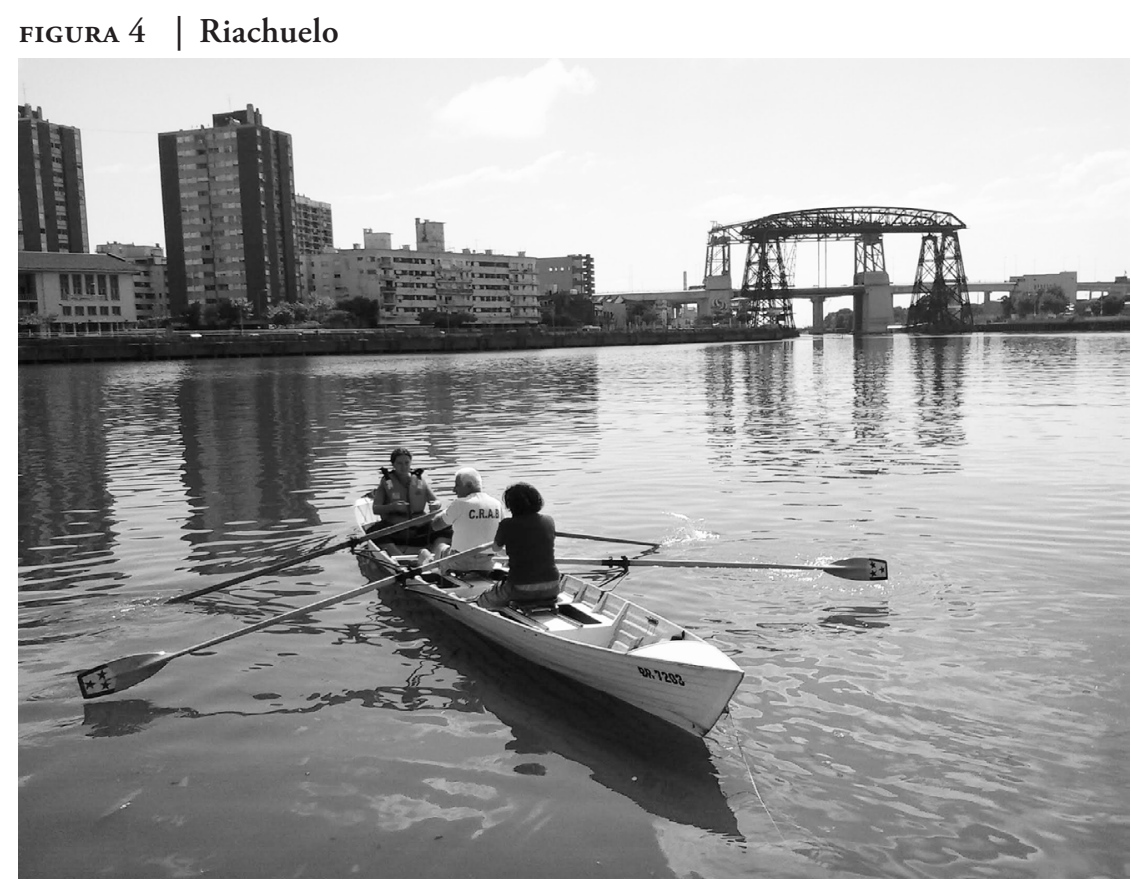

FUENTE FOTOGRAFÍA DE LA AUTORA 
Figuras 5, 6 y 7 | Conventillos de La Boca
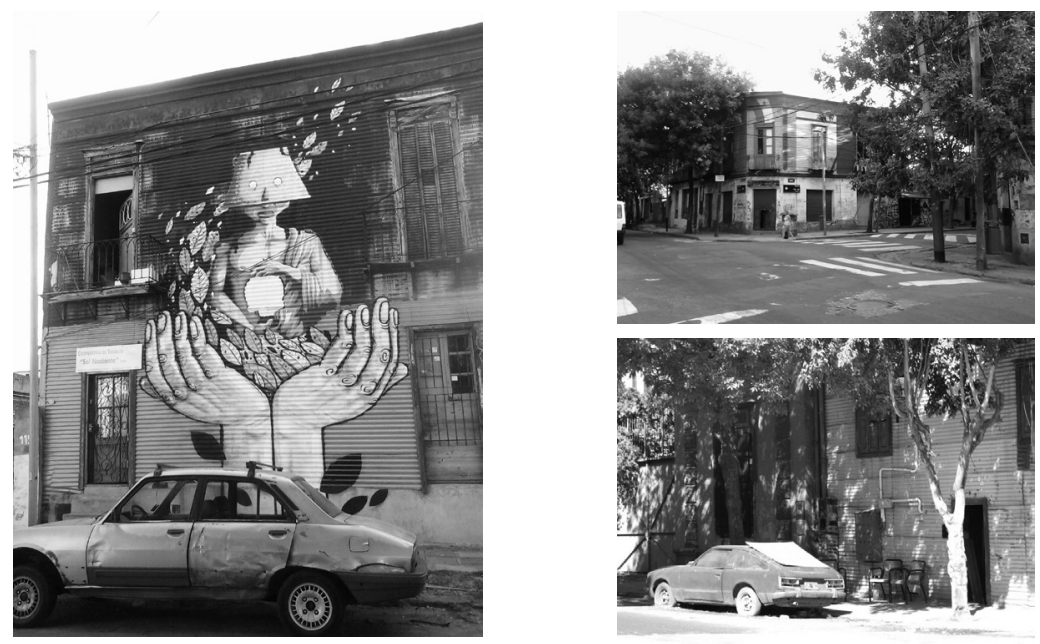

FUENTE FOTOGRAFÍAS DE LA AUTORA

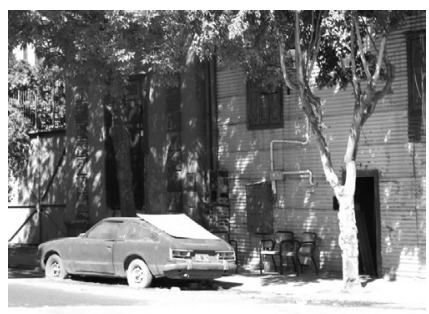

Según algunas versiones, los conventillos que hoy distinguen el área fueron inicialmente levantados por inmigrantes genoveses que llegaron a esta zona a finales del siglo XIX (Lacarrieu, 2007). Efectivamente, en aquel momento, la vivienda conventillo predominaba claramente en La Boca (Municipalidad de la Ciudad de Buenos Aires, 1988, p.15). Casi un siglo después, en 1980, el porcentaje de la población boquense que habitaba en vetustos inquilinatos era aún muy elevado, totalizando el 36\% de los hogares contra un total de 3,2\% que presentaba la Capital (Municipalidad de la Ciudad de Buenos Aires, 1988, p. 22). Si bien ese porcentaje descendió al 17,6\% en 2001 (Redondo \& Singh, 2008, p. 113), la cifra sigue siendo muy alta en comparación con la media de la ciudad, que rondaba el $3 \%$.

Hoy en día, La Boca pertenece a una de las dos comunas de la ciudad (la Comuna 4) que presentan los índices más elevados de hogares residentes en piezas de inquilinato (el 4,98\%, contra un $2,2 \%$ de la Capital en su conjunto) 3 $^{3}$ Según el Censo Nacional 2010, continúa registrando además los mayores índice de pobreza, junto a otros barrios localizados igualmente en la zona sur de la ciudad (Comisión de Vivienda del Consejo Económico y Social, 2013, p. 28).

La alta concentración de instituciones dedicadas al desarrollo de actividades sociales y comunitarias (comedores, merenderos, centros que brindan apoyo escolar, bachilleratos populares, cooperativas de vivienda, radios comunitarias, y otras) y la presencia de una importante comunidad de artistas independientes que residen, poseen sus talleres y desenvuelven su actividad creativa en La Boca, son otros elementos que singularizan ese espacio. Ciertamente, desde el momento en

3 No se dispone de datos acerca del número de hogares que residen actualmente en inquilinatos en La Boca, ya que el último Censo Nacional (2010) no desagrega la información por barrios, sino por comunas. Lo que es seguro es que el porcentaje citado sube notoriamente para el caso de La Boca, aunque no podemos decir a qué cifra. 
que el reconocido artista boquense Benito Quinquela Martín (1890-1977) y otras destacadas figuras -Alfredo Lazzari, Fortunato Lacámera, Eugenio Daneri, Víctor Cunsolo, Miguel Carlos Victorica- comenzaron a retratar el paisaje local, y otras a animarlo con su música, el barrio de La Boca quedó fuertemente asociado a las artes y la cultura ${ }^{4}$ (Thomasz, 2014, p. 95). Además de haber encontrado en el paisaje boquense una poderosa fuente de inspiración estética, Quinquela Martín legó importantes instituciones al barrio: inauguró la Escuela Museo Pedro de Mendoza en 1936, fundó el lactario y el jardín de infantes, creó el Instituto Odontológico Infantil y construyó el Teatro de la Ribera (Iparraguirre, 2001, p. 14). Asimismo, en el decenio de 1950 intervino artísticamente las fachadas de los conventillos ubicados en una callejuela del barrio hoy conocida como Pasaje Caminito.

\section{FIGURA 8 | Viviendas precarias de La Boca}

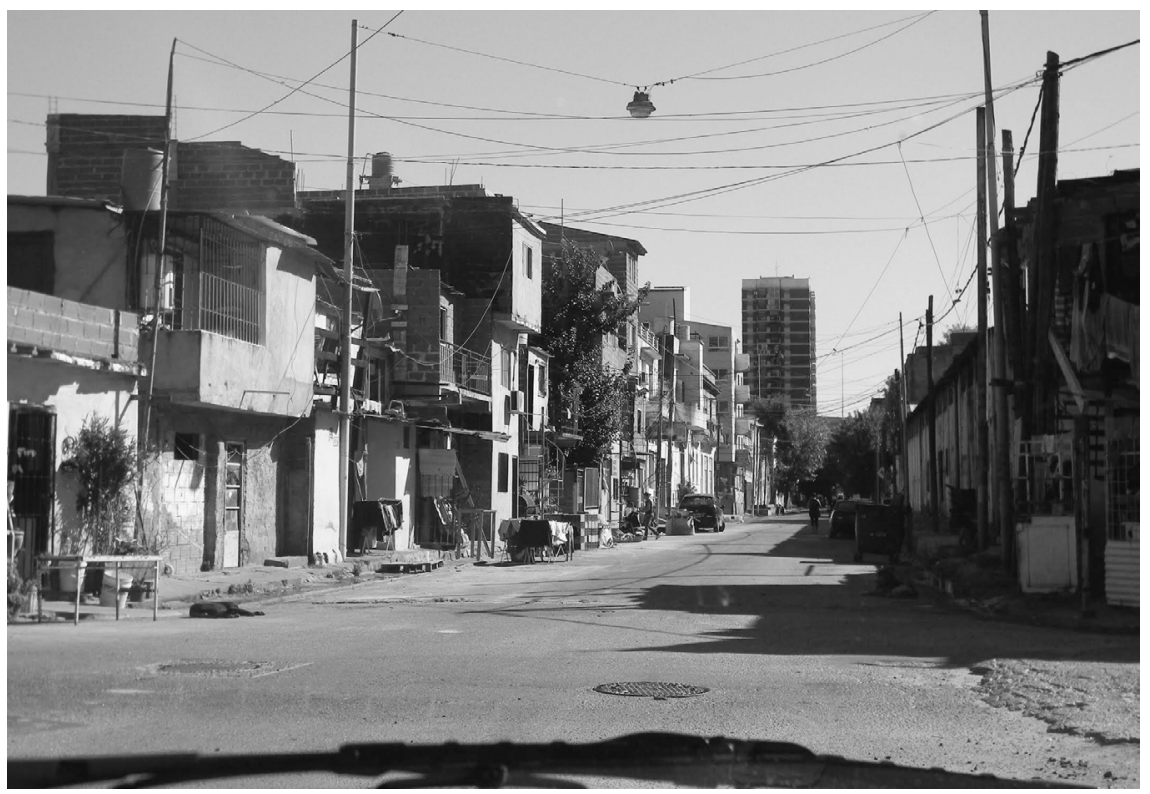

FUENTE FOTOGRAFÍA DE LA AUTORA

Un pequeño circuito turístico enclavado junto a la boca del Riachuelo y el Pasaje Caminito comenzó a forjarse en ese rincón de la ciudad a instancias de la actividad artística que allí tenía lugar. Pintores, bailarines, cantores de tango, artesanos y artistas callejeros se instalaron en el lugar, mientras que algunos viejos conventillos fueron reconvertidos en galerías comerciales, tiendas, restaurantes o ateliers (Lacarrieu, 2007, p. 52).

4 Se conoce con el nombre de Grupo o Escuela de La Boca al conjunto de artistas plásticos de ascendencia predominantemente italiana y orígenes humildes que vivieron en la zona del Riachuelo, se inspiraron en el paisaje boquense (Riachuelo, puerto, calles, barcos) y lo plasmaron en sus obras. A los ya mencionados pueden agregarse Del Prete, Rosso, Tiglio, Menghi, Pacenza, Mandelli, Diomede y Stagnaro (Iparraguirre, 2001, p.10). 
El de La Boca constituye, en síntesis, un barrio periférico y empobrecido de origen proletario y tradición combativa ${ }^{5}$, dotado de un circuito turístico, en el que los sectores populares coexisten junto a una comunidad de artistas independientes y algunos representantes de las clases medias.

\section{La movilización vecinal}

A mediados de 2012 comenzó a resonar en La Boca la noticia relativa a la inminente aprobación de un proyecto de ley que convertiría ese espacio urbano en un "Distrito de las Artes”. Una versión preliminar de la normativa se difundió entre los vecinos. De alguna manera, dicho proyecto retomaba la reputación artístico-cultural del barrio forjada en torno a la obra de Quinquela Martín y la Escuela de La Boca. Contrariamente a lo que el poder público había previsto, vecinos, artistas, trabajadores públicos (maestros, médicos, trabajadores sociales), militantes y miembros de organizaciones comunitarias, sociales, culturales y políticas boquenses comenzaron a movilizarse objetando el proyecto. Se trataba en su mayoría de agrupaciones peronistas, kirchneristas o de izquierda opositoras al PRo (Propuesta Republicana), el partido de derecha que gobierna la ciudad desde 2008. En consecuencia, se desarrollaron diversas reuniones en distintas instituciones locales -el Club Boca Juniors, la sede de los Bomberos Voluntarios, la Sociedad Luz, la Galería de Arte Popa, el teatro Verdi, y otras-, a las que asistieron tanto los actores sociales boquenses recién referidos como los funcionarios del Gobierno de la Ciudad de Buenos Aires que impulsaban la ley (algunos de esos encuentros fueron, de hecho, convocados por funcionarios públicos oficialistas, con la intención de neutralizar la incipiente movilización vecinal). En el marco de esos encuentros, que resultaron ser muy masivos, vecinos, trabajadores y representantes de organizaciones boquenses pudieron verter sus opiniones respecto del proyecto de ley ${ }^{6}$. Aunque su posicionamiento ante la creación del distrito fue de resistencia y repudio, la ley fue finalmente aprobada de manera unilateral por la Legislatura de la Ciudad de Buenos Aires el 2 de noviembre de 2012.

Así, a los interrogantes planteados se añade el siguiente: ¿por qué una normativa destinada en primera instancia a apoyar y fortalecer la actividad cultural del barrio, que retoma la tradición local vinculada a la figura de Quinquela y la Escuela de La Boca, fue resistida por gran parte de los artistas, vecinos y militantes del barrio?

\section{La resistencia y el discurso vecinal}

El trabajo etnográfico realizado en las instancias en las que se discutió el proyecto de ley indica que el repudio ante este último se concentró alrededor de algunos ejes centrales, tales como derecho a la vivienda, desarrollo urbano, patrimonio e identidad. No obstante, las primeras objeciones de los vecinos fueron generales. Remarcaron

5 En la zona de La Boca, Barracas y San Telmo se desató en 1907 la famosa Huelga de Inquilinos, que constituyó la primera protesta porteña importante fundada en motivos habitacionales. Se originó a raíz de un arbitrario aumento en los impuestos municipal y territorial, y se propagó al interior del país.

6 El espacio urbano afectado al Distrito de las Artes incluye el barrio de La Boca en su totalidad, pero comprende solo pequeńos sectores de los barrios aledańos de Barracas y San Telmo. De allí que el debate público sobre el tema tuviera su epicentro en La Boca. 
que el articulado de la ley había sido realizado por el Estado de manera unilateral, sin haberles dado participación y sin haberlos convocado ni consultado. Cuestionaron que, pese a que se trata de una norma que supuestamente se orienta a apoyar la actividad cultural y artística del barrio, su autoridad de aplicación fuera el Ministerio de Desarrollo Económico y no el Ministerio de Cultura (Thomasz, 2013). Impugnaron el léxico empresarial y de tinte economicista que impregna la normativa y señalaron que su articulado "no dice la palabra artistas ni una sola vez". Sostuvieron que la ley no tiene como propósito promover el desarrollo artístico o cultural del barrio ni potenciarlo, sino que constituye un "negocio inmobiliario encubierto" que expulsará a los vecinos de La Boca, especialmente a los sectores populares.

Efectivamente, múltiples cuestionamientos remitieron al derecho a la vivienda. Fueron recurrentes las voces que expresaron que la virtual puesta en vigencia de la ley atentará contra el derecho a la vivienda que, de manera trabajosa, lograron construir los sectores populares que habitan en los conventillos, inquilinatos, casas tomadas y viviendas autoconstruidas del barrio. Señalaron que la ley constituye un negocio que favorecerá la especulación inmobiliaria y la apropiación de las tierras e inmuebles locales por parte del sector privado, incrementará el valor de los alquileres, precipitará más desalojos, generará más exclusión social y la expulsión de los sectores populares del barrio. Así se expresaba Ulrico, militante de una importante organización social y política local, en la reunión vecinal que tuvo lugar en la Sociedad Luz en septiembre de 2012: "Este proyecto no requiere inversión por parte del Poder Ejecutivo. No hay destino de fondos. Los únicos beneficiarios serán empresas. Se verán afectadas las familias en emergencia y los vecinos que alquilan casas en malas condiciones. Los dueños las van a vender y van a expulsar a familias con muchos ańos de arraigo en La Boca. No hay destinados terrenos específicos al proyecto, sino que son propiedades privadas y facilidades para que las empresas tengan acceso a las tierras".

Otros señalamientos expresaron que el proyecto de ley perjudicará además a los ciudadanos de clase media que ya residen en La Boca pero que no presentan vínculos con las actividades artístico-culturales. Sostuvieron que si la ley ofrece incentivos económicos a inversores y empresarios, no propone ningún tipo de beneficio directo a los vecinos que ya habitan en el barrio. Así, militantes de organizaciones sociales boquenses destacaron la paradoja derivada del hecho de que los empresarios quedarán exentos del pago de ABL, mientras que los vecinos de la zona deberán afrontarlo. Según las palabras de la trabajadora social Graciela en la Sociedad Luz: "Los beneficios son exención de ABL; pero los vecinos del barrio van a pagar más caros sus impuestos y los empresarios con dinero no van a pagar nada por diez años”.

Varios artistas que residen en La Boca y desarrollan sus actividades creativas allí aseveraron que, en rigor, a ellos la ley tampoco los favorece. Remarcaron que es sumamente engańosa y que una lectura atenta de su articulado indica que su aplicación práctica no reporta ninguna ventaja económica relevante para los artistas pequeńos e independientes ya establecidos en el área, ni para los centros culturales y organizaciones artísticas comunitarias boquenses. Aclararon que en tanto ellos no ejercen actividades económicas que supongan el pago de Ingresos Brutos, el único 
beneficio del que podrían gozar es la exención del ABL (la exención del Impuesto de Sellos no les compete, ya que solo afecta a quienes adquieran propiedades).

Con respecto a esta cuestión, cabe señalar que la ley parte de la falaz premisa de que las artísticas o culturales constituyen necesariamente actividades comerciales o lucrativas volcadas al mercado, y de que los artistas que habitan en La Boca generan forzosamente ganancias económicas a partir de dicha actividad. Se desconoce y omite así que, en no pocos casos, aquellos se ganan su sustento dedicándose a actividades extraartísticas, complementan sus ingresos con los aportes realizados por otro miembro del grupo familiar, o simplemente encuentran en el arte un modo de expresión (antes que de subsistencia).

Algunos vecinos señalaron críticamente que la legislación no diferencia entre artistas independientes e inversores externos. Los beneficios que la norma propone a ambos actores son los mismos y, según se indicó, en la práctica favorece en una proporción mucho mayor a los inversores externos. La figura que cuestionaron en tal sentido fue la de "desarrolladores de infraestructura artística". Así se pronunciaba Alex, dirigente del Partido Socialista local, en la Sociedad Luz: "No es un proyecto de cultura, sino para inversores. Más de un tercio de los artículos son de desgravaciones impositivas. No diferencian entre los artistas que ya están en el barrio de La Boca, que no tienen capacidad tributaria, respecto de los grandes inversores, que son grandes empresas".

En efecto, las desgravaciones impositivas que constituyen un beneficio para un inversor externo interesado en adquirir una propiedad y ejercer actividades comerciales (en especial la exención del Impuesto de Sellos y del pago de Ingresos Brutos) no representan ninguna ventaja para las agrupaciones culturales o comunitarias ni para los artistas independientes ya arraigados en el barrio que no desarrollan actividades lucrativas (y que, en consecuencia, no pagan ni deben pagar Ingresos Brutos). $\mathrm{Al}$ contrario, pueden representar un riesgo, especialmente para aquellos artistas o agrupaciones culturales que alquilan los inmuebles en los que desenvuelven sus actividades, ya que los propietarios de dichos inmuebles pueden optar por darles otros usos más rentables, acogiéndose a los beneficios económicos que propone la ley. Sin desconocer que los deteriorados conventillos de La Boca constituyen el eslabón más endeble de la cadena de valores inmobiliarios -el más proclive a ser codiciado y apropiado por los desarrolladores-, algunos agentes culturales y artistas señalaron que su propio derecho a la vivienda y a permanecer en el barrio se verá también amenazado, pues no son pocos los que son locatarios, desarrollan su actividad creativa allí y residen en las viviendas-talleres o espacios que alquilan. De allí que una modificación en la legislación directamente vinculada con el acceso al suelo urbano, como la representada por el Distrito de las Artes, sea vista por ellos como una afrenta antes que como un incentivo. Según el planteo esbozado por Alejo, un artista plástico independiente, en la Sociedad Luz: "Los artistas tenemos que tener claro que esto es un negocio de tres o cuatro que vienen a reventar el barrio, que rompe las tramas sociales existentes. Y los artistas tienen que tener claro que esto no se hace por el arte, sino solo por los negocios. Nos echan del barrio por la suba del valor de los metros cuadrados. Hay que pelear para que no quedemos afuera los artistas plásticos populares y marginales". 
Por su parte, un vecino independiente se manifestaba del siguiente modo en la reunión realizada en los Bomberos Voluntarios de La Boca en octubre de 2012: "Parece que La Boca no tuviera ciudadanos, que fuera un lugar desértico. No se consultó ni a artistas ni a vecinos supuestamente beneficiados por este proyecto. No tiene en cuenta la historia del barrio de La Boca. No hace falta un proyecto que traiga artistas, hay muchos. Es un disfraz para un proyecto inmobiliario". Otra vecina y artista del barrio llamada Amalia, perteneciente a un centro cultural comunitario, sostuvo en un encuentro organizado en el Teatro Verdi que la ley "no tiene nada que ver con la promoción de las artes, la cultura. Es un curro inmobiliario. Es totalmente expulsiva de pequeños artistas". La ley estimula la instalación en La Boca de los "grandes conglomerados" vinculados a las industrias culturales y del entretenimiento, "da entrada a las grandes cadenas de librerías, de tanguerías para turistas", pero no beneficia ni a los artistas ni a los centros culturales del barrio, agregaba un representante de un centro cultural del barrio en una de las reuniones desarrollada en la Sociedad Luz.

Algunos vecinos e integrantes de organizaciones sociales agregaron que la ley prepara el terreno para un proceso de privatización, mercantilización y espectacularización de las expresiones artístico-culturales locales similar al que tuvo lugar en Caminito, donde viejos inquilinatos y conventillos fueron adquiridos por inversores, desalojados y reconvertidos en ateliers, tanguerías, restaurantes o locales comerciales "temáticos" para disfrute de turistas ${ }^{7}$ (Lacarrieu, 2007, p. 52).

"Caminito es un antecedente del Distrito de las Artes. Se privatizó y se transformó en un lugar en el que tres o cuatro capitalistas se quedaron con todo. No generaron trabajo, no abrieron el arte en representación de todos”, señalaba Jimena, integrante de una organización social boquense, en la Sociedad Luz.

La creación del Distrito de las Artes constituye un proceso que probablemente desplace a las actividades culturales comunitarias, independientes y no mercantiles que se desarrollan desde hace tiempo en el barrio. Efectivamente, algunos sostuvieron que los cambios promovidos por la ley perfilan a La Boca como un espacio atractivo para los sectores sociales más acomodados y como polo turístico dedicado a la exhibición y el consumo contemplativo de grandes espectáculos culturales, antes que como lugar de desarrollo de actividades sociales y comunitarias, de residencia de sectores populares, trabajadores y pequeños artistas independientes y, por ende, de producción o actividad artística y creativa independiente. La inauguración de la Usina de las Artes y los selectos espectáculos que se brindan allí son un símbolo de esa tendencia, que fue cuestionada por militantes y vecinos. Según las palabras de una integrante de una asociación artístico-cultural boquense, en la Sociedad Luz: "La Boca ya tiene producción cultural, pero no se habla de incentivar la ya existente. La Usina de las Artes es financiada por todos los vecinos, pero allí solo accede la elite del barrio. Esto es un negocio inmobiliario que no tiene que ver con la producción artística". "Al $\mathrm{PRO}^{8}$ no le importa la cultura, hacen cultura para unos pocos, negocios en torno a la cultura. A

7 Para un análisis acerca de la reconversión comercial de los conventillos de Caminito se sugiere consultar el texto de Lacarrieu (2007).

8 Se recuerda que PRo es el nombre del partido político liderado por el exempresario Mauricio Macri, Jefe de Gobierno de la Ciudad de Buenos Aires al momento de escribirse este artículo. 
los vecinos del barrio no les va a dar trabajo ni asegurar vivienda, todo lo contrario", agregaba un militante del Partido Comunista.

Adicionalmente, se objetaron los vínculos que el oficialismo establece entre la creación del distrito y el pretendido "desarrollo", "crecimiento económico" o "progreso" que traería aparejado, así como las virtuales fuentes de trabajo que pudiera generar: "El Distrito de las Artes es una política liberal. Es teoría del derrame pensar que solo por plantear el desarrollo económico de empresarios, va a mejorar La Boca. No van a contratar a nadie del barrio. La gente del barrio necesita trabajar en el barrio. Los empresarios no piensan en dar trabajo genuino a la gente", expresaba la trabajadora social Graciela en la Sociedad Luz. Así se pronunciaba Juan, militante de una importante organización social y política local, en la sede de los Bomberos Voluntarios: "Venimos a expresar nuestro repudio a este proyecto de desarrolladores urbanos. No estamos en contra del desarrollo urbano. Para eso luchamos hace rato. Pero el desarrollo tiene que ser para los vecinos, las agrupaciones locales. Esto es volver a los ańos noventa, es teoría del derrame, si les dan exenciones impositivas a los que no lo necesitan. Este proyecto genera injusticia. El desarrollo no puede ser impuesto desde arriba y no atender a las necesidades de los vecinos". Por su parte, la militante Analía agregaba lo siguiente: "Todos queremos desarrollo, los médicos, los artistas, todos. Pero desarrollo ¿para quién? El proyecto no dice que va a financiar a los artistas, ni siquiera está fomentado por la Secretaría de Cultura. No estamos contra el progreso, pero esto es negocio inmobiliario. Mi marido es músico del barrio y no lo invitan a tocar a la Usina. Cuarenta pesos tenemos que pagar los

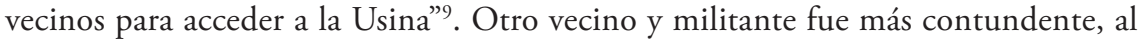
manifestarse de esta manera en el mismo encuentro:

Vengo a reivindicar el derecho a vivir en la ciudad. Nadie se opone al desarrollo. Claro que tiene que haber inversión. Acá lo que se discute es si la inversión se hace con el pueblo o sin el pueblo. La dicotomía no es inversión sí o inversión no. Se necesita inversión, pero para el pueblo. Reivindico el derecho a vivir en la ciudad. Este proyecto lo que está planeando es barrer a los pobres al otro lado del Riachuelo, cuando no tirarlos al Riachuelo (testimonio de Mario).

Se señaló ya que a la hora de diseñar el proyecto de ley, el Estado retomó la reputación artística de La Boca, ubicando la nueva iniciativa en una línea de continuidad con dicha identidad. No obstante, otra impugnación que resonó con fuerza indicaba que en lugar de constituir un reconocimiento a la identidad local, la disposición representaba una abierta amenaza a esta última, así como a su patrimonio arquitectónico, histórico y cultural y a su tejido social: "El proyecto no contempla el patrimonio histórico ni edilicio del barrio. Hay cosas mucho más importantes acá, como la educación, el aumento de los desalojos. La Boca ya es un Distrito de las Artes desde el siglo pasado y desde Quinquela, desde Fortunato Lacámera. No hace falta que lo nombren así ahora", sostenía un vecino independiente en la sede de los Bomberos Voluntarios.

En cuanto al tejido social boquense -conformado por las abigarradas tramas que existen entre los vecinos que residen en los conventillos, que asisten a los

Testimonio vertido el 15 octubre de 2012 en la sede de los Bomberos Voluntarios de La Boca. 
merenderos, comedores comunitarios, bachilleratos populares y otras instituciones sociales y culturales-, algunas voces señalaron que el proyecto de ley provocará su desarticulación, una vez que los grandes inversores inmobiliarios, favorecidos por las exenciones que propone la ley, tiendan a apropiarse de los inmuebles de la zona desplazando a la población y las actividades que se desarrollan actualmente allí. Así se expresaba un militante kirchnerista en un encuentro realizado en el Teatro Verdi: "Mirá si vienen y tiran abajo los conventillos de chapa y madera e invierten en torres". "Vamos a ver brotar grandes edificios. Es impresionante el desastre social que van a generar".

Varios vecinos y militantes sociales remarcaron que la norma equivale a una escandalosa inversión del ideario quinqueliano. Destacaron que la impulsada por el Grupo de La Boca constituyó una actividad creativa férreamente comprometida con la realidad local, preocupada por promover lo que hoy llamaríamos el desarrollo social. Y que el nuevo Distrito de las Artes, lejos de continuar dicho ideario, entra en abierta tensión con él. Si Quinquela legó al barrio una serie de instituciones y emprendimientos comprometidos con la integración social de sus pobladores, la actual ley Distrito de las Artes tenderá a desplazar y excluir a la población local. “Toda la plata que ganó vendiendo cuadros, compró tierras en la Ribera y las puso al servicio del pueblo haciendo un polo cultural y artístico, que es lo que le da de comer al barrio" decía un vecino, militante y arquitecto de nombre Gerardo en la Sociedad Luz. Por su parte, el director de una reconocida institución cultural boquense dedicada al teatro comunitario recordaba, en la sede de los Bomberos Voluntarios, que Quinquela "dejó un teatro, una biblioteca, una escuela y otras cosas para el barrio. Esperar que el mercado derrame y desarrolle el barrio es una utopía. En la Usina de las Artes no hay talleres, nada que sea para el barrio. Son lindos nombres, pero sin la gente del barrio no hay desarrollo". Al respecto, una nota publicada en un periódico barrial aseveraba que cuando el reconocido pintor creó el Complejo Cultural de La Boca, "sentó como eje la integración cultural, educativa y sanitaria del barrio". Mientras que sobre la coyuntura actual agregaba lo siguiente:

No puede soslayarse la crisis habitacional que sufre La Boca, en la que conviven desalojos, hacinamiento, incendios e inmuebles ociosos, y que un proyecto de este calibre con eje en lo inmobiliario va a generar un impacto ineludible. Para que la promoción de un Distrito de las Artes interactúe con el barrio, además de definir una política cultural, sería imprescindible el acompañamiento de otras normas que apuntalen la situación de la vivienda, que incluso padecen muchos artistas del barrio. Porque si el Estado deja "liberado" este diagnóstico crítico a las leyes del mercado, el resultado estará cantado de antemano. Nada más alejado del legado quinqueliano (Luciano Beccaria, periodista del periódico Sur Capitalino).

La figura 9 sintetiza gráficamente el modo en que -tal como lo subrayan los testimonios recogidos hasta aquí-, en términos comparativos, la ley favorece efectivamente a inversores o empresarios que adquieran inmuebles o terrenos y que construyan obras nuevas, en desmedro de los actores sociales de escaso poder adquisitivo ya establecidos en la zona. 

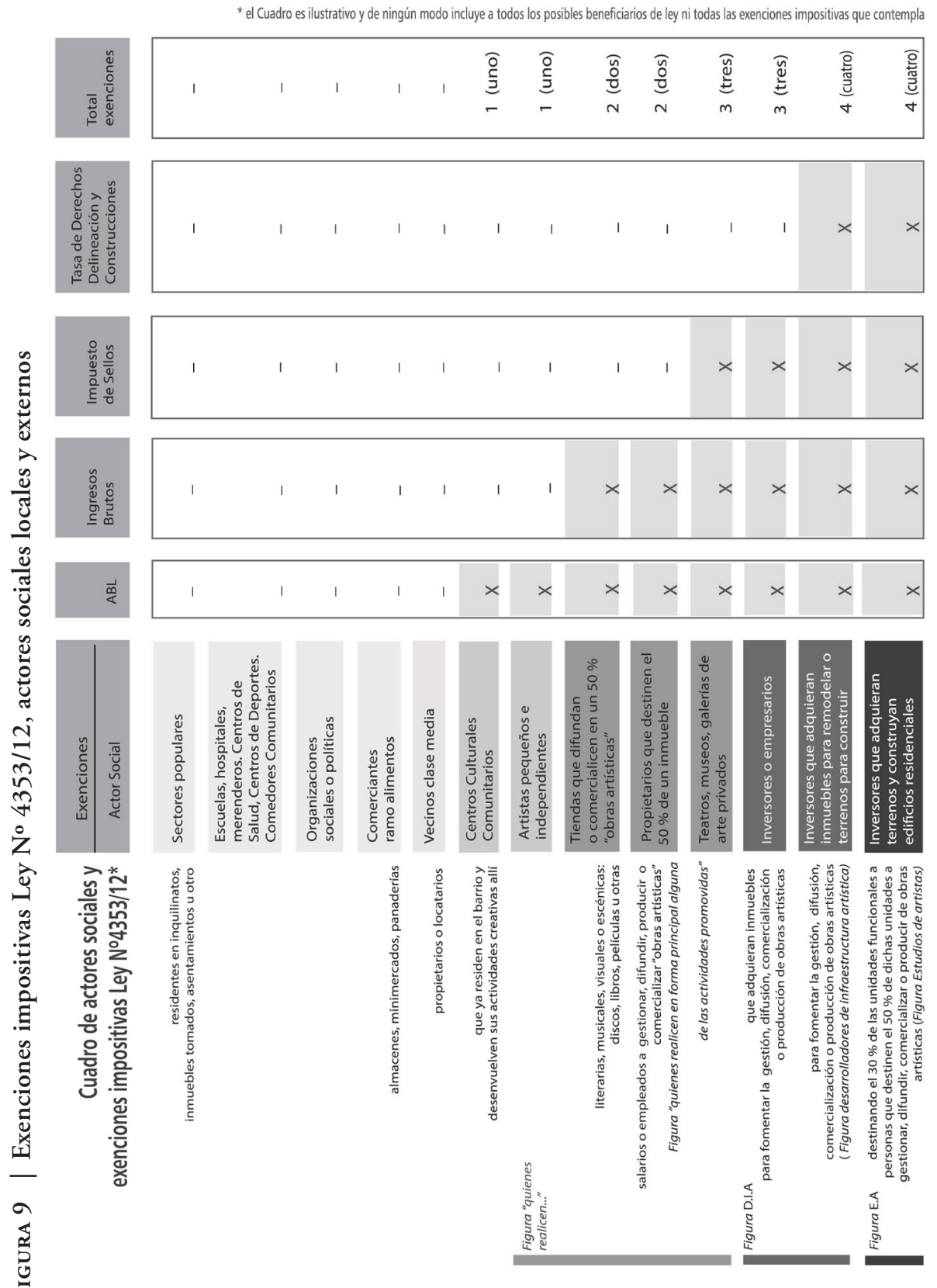
Para finalizar este apartado, es interesante notar que las críticas de los vecinos a la creación del Distrito de las Artes recapituladas a lo largo de esta sección reivindicaron los diversos derechos económicos, sociales y culturales que integran la Carta Mundial por el Derecho a la Ciudad (смDC). De hecho, sin proponérselo y, en la mayoría de los casos, sin siquiera conocer ese documento, los vecinos cuestionaron el incumplimiento de los enunciados contenidos allí. En el próximo apartado se analizan entonces sus impugnaciones articulándolas con los derechos consignados en la CMDC.

\section{La Carta Mundial por el Derecho a la Ciudad}

La noción de derecho a la ciudad fue inicialmente propuesta por un reconocido exponente de la Escuela Francesa de Sociología Urbana -Henri Lefebvre (1973)-, a fin de cuestionar la excesiva subordinación del espacio urbano a las necesidades de la industria y del capital. Pero dicha noción ha sido largamente revisada y resignificada, como recientemente se ha hecho en la $\mathrm{CMDC}^{10}$. En esta se conceptualiza el derecho a la ciudad como un derecho complejo e integral, que presenta varios componentes: el derecho a la vivienda, al trabajo, a un medioambiente sano y sostenible, al desarrollo, a la participación en la planificación y gestión urbana, al patrimonio y a la herencia histórica y cultural (Art. 1).

Mediante figuras tales como la "función social de la ciudad", la CMDC incorpora también elementos que remiten a la problemática de la integración, del vínculo social y el ejercicio de ciudadanía. Afirma que las ciudades deben ejercer una función social, garantizando a todos sus habitantes "el usufructo pleno de los recursos que la misma ciudad ofrece" y asumiendo la realización de proyectos e inversiones en beneficio de la comunidad urbana en su conjunto. Sostiene, además, que las políticas urbanas deben promover el uso socialmente justo del espacio urbano e "inhibir la especulación inmobiliaria” (Art. 2): "En la formulación e implementación de las políticas urbanas debe prevalecer el interés social y cultural colectivo por encima del derecho individual de propiedad y los intereses especulativos".

Con respecto al ejercicio de ciudadanía, la CMDC incorpora el principio de no discriminación y el derecho "a la igualdad de derechos" (Mathivet, 2010, p. 26): asevera que todas las personas tienen derecho a la ciudad sin discriminaciones de ingreso, etnia y género (Art. 1), y que las urbes deben asegurar el bienestar colectivo de sus habitantes en condiciones de igualdad, equidad y justicia (Art. 2).

El documento hace también hincapié en el desarrollo urbano, señalando que la planificación y la gestión urbano-ambiental deben garantizar el equilibrio entre el desarrollo urbano y la protección del patrimonio histórico, arquitectónico, cultural y artístico e impedir la segregación y la exclusión territorial (Art. 5).

10 La Coalición Internacional de Hábitat (HIC), el Foro Nacional por la Reforma Urbana de Brasil y el Frente Continental de Organizaciones Comunales (FCOC) son algunas de las agrupaciones que participaron en la elaboración de la Carta Mundial por el Derecho a la Ciudad. Sus contenidos fueron discutidos en el Foro Social de las Américas (Quito, julio 2004), el Foro Mundial Urbano (Barcelona, octubre 2004) y el Foro Social Mundial (Porto Alegre, enero 2005).Véase onuHabitat (2004). 
Como se adelantó, las críticas de los vecinos de La Boca contra la creación de un Distrito de las Artes aludieron al conjunto de derechos recién enumerados. Desde su perspectiva, la puesta en vigencia de esa normativa va contra el cumplimiento efectivo de tales derechos, los vulnera o violenta. Así, los testimonios antes reproducidos objetaron que el proyecto había sido elaborado por el poder de manera unilateral, vulnerando el principio de participación en la planificación y gestión urbana. Aseveraron que el derecho a la vivienda de los sectores populares que habitan en inquilinatos, de artistas y vecinos de clase media que arriendan sus talleres o viviendas se verá fuertemente comprometido, dada la presión que ejercerá el sector inmobiliario, acicateado por las facilidades económicas que se le ofrecen. Expresaron que lejos de limitarla, el proyecto de ley fomenta la especulación inmobiliaria. De resultas, indirectamente señalaron que va contra la función social de la ciudad. También indirectamente, sostuvieron que vulnera el derecho "a la igualdad de derechos” (Mathivet, 2010, p. 26) y el principio de no discriminación, por cuanto según denunciaron- brinda un trato diferencial a empresarios e inversores externos, a quienes se favorece a expensas de los ciudadanos que ya residen en el área. Cuestionaron enérgicamente el modelo de desarrollo que pretende impulsar la normativa, al señalar que no tiene como propósito promover el desarrollo social de la población local ni generar fuentes de trabajo para esta última, sino que fomenta el desarrollo urbano especulativo y la apropiación privada del suelo urbano. Denunciaron que dicho modelo va contra la protección del patrimonio en todas sus variantes, indicaron que desarticulará las redes sociales y el tejido social local, y que atenta también contra la identidad barrial. Aseveraron críticamente, por último, que generará un fuerte proceso de segregación y de expulsión socioterritorial ${ }^{11}$.

\section{Conclusiones}

Pese a las duras críticas de vecinos, representantes de organizaciones y trabajadores públicos, el proyecto fue finalmente aprobado a fines de 2012. Solo se introdujeron ciertas modificaciones menores al proyecto de ley preliminar. No obstante, en respuesta tácita e indirecta a la movilización vecinal, el oficialismo incorporó un artículo que merece un comentario aparte, el 29, aunque sin arbitrarse ninguna medida concreta tendiente a resguardar el derecho a la vivienda de la población local ni a refrenar las dinámicas expulsivas: "El Poder Ejecutivo, a través del órgano que corresponda, atenderá la situación de vulnerabilidad social en la zona, relevando la necesidad de soluciones habitacionales y dispondrá acciones direccionadas a facilitar la permanencia de las familias radicadas actualmente en el Distrito de las Artes" (Ley No 4353/12, Art. 29).

11 Algunos aspectos seńalados por los vecinos (establecimiento de instituciones del sector artístico, valorización inmobiliaria) presentan puntos de contacto con los fenómenos de gentrificación. Determinar en qué aspectos los cambios que se registran en La Boca corresponden a un proceso de gentrificación no ha sido un objetivo del presente trabajo. Se analizaron las argumentaciones de los vecinos desde el marco que ofrece la CMDC, por cuanto resultaba más iluminador para examinar los posicionamientos de la población local. 
La incorporación de dicho artículo no trascendió entre el nutrido grupo de vecinos, militantes y trabajadores que se movilizaron. Imperaba entre ellos la decepción y la bronca por no haber podido evitar la aprobación de la ley. Para los pocos vecinos que sí se enteraron de su existencia, el Artículo 29 representó una modificación retórica incapaz de conmover el espíritu profundamente liberal de la ley. Fue interpretada como un gesto de "corrección política" de parte del oficialismo antes que como una sincera declaración de principios (y, efectivamente, era un gesto de corrección política).

Actualmente, el contexto político y la correlación de fuerzas es sumamente desfavorable para los sectores vulnerables y empobrecidos, los artistas independientes y trabajadores boquenses, puesto que sus intereses gravitan mucho menos que los de inversores, empresarios y representantes del sector inmobiliario. Empero, quizás hoy en día el Artículo 29 constituya -junto a otros instrumentos legislativos locales y nacionales que resguardan el derecho a la vivienda, y junto a recomendaciones y documentos internacionales que tutelan el derecho a la ciudad, tales como la CMDC- un intersticio, un resquicio o fisura para emprender una nueva lucha. Vale decir, para intentar contener el proceso expulsivo que ya se encuentra en marcha, para promover modificaciones en la reglamentación de la Ley $\mathrm{N}^{\circ} 4353 / 12$, de suerte que el Artículo 29 no sea letra muerta, sino que derive en la instrumentación efectiva de medidas progresivas que resguarden el derecho a la vivienda y a la ciudad de los sectores populares y vecinos que siempre han habitado en La Boca.

Para finalizar, es importante apuntar que los procesos expulsivos que ya se avizoraron en La Boca no resultan ajenos al resto de los distritos. Aunque las observaciones realizadas no pueden trasladarse mecánicamente a las áreas afectadas por los otros distritos propuestos (por cuanto se registran diferencias históricas y socioeconómicas al interior de cada uno de ellos), cabe remarcar que todos fueron creados con la misma lógica. Por ende, tienden también a promover el desarrollo urbano especulativo, a debilitar el cumplimiento de los derechos contenidos en la cMDs y lo que allí se consigna en términos de "la función social de la ciudad". Mancomunar esfuerzos con militantes, trabajadores y sectores populares también afectados por la política de creación de distritos "creativos" -y, cabe agregar, expulsivos y excluyentes- es quizás el desafío que se abre en esta nueva etapa, en la que los desalojos y la segregación socioespacial parecen estar promovidos por ley.

\section{Referencias bibliográficas}

Amin, A. \& Cohendet, P. (2004). Architectures of knowledge; firms, capabilities, and communities. Oxford: Oxford University Press.

Beccaria L. (2012). El proyecto impuesto. Sur Capitalino, 21(212), 5-7. Disponible en http:// surcapitalino.com.ar/edimpresa_descarga.php?Id=44

Blaisten, I. (2001). Entre la bohemia y el rigor formal. Pintura Argentina. Panorama del periodo 1810-2000. Pintores de La Boca I, 19, 5-8. Buenos Aires: Banco Velox.

Du Gay, P. (Ed.) (1998). Production of culture/Cultures of production. Londres: Sage Publications. 
Du Gay, P. \& Pryke, M. (Eds.) (2002). Cultural economy: Cultural analysis and commercial life. Londres: Sage Publications.

Featherstone, M. (1991). Consumer culture and postmodernism. Londres / Newbury Park: Sage.

Florida, R. (2002). The rise of the creative class: And how it's transforming work, leisure, community and everyday life. Nueva York: Basic Books.

Florida, R. (2005). Cities and the creative class. Nueva York: Routledge.

Grabher, G. (2001). Ecologies of creativity: The village, the group, and the heterarchic organisation of the British advertising industry. Environment and Planning A 33(2), 351-374. doi: 10.1068/a3314

Redondo, A. \& Zunino Singh, D. (2008). El entorno barrial: La Boca, Barracas y San Telmo. Reseña histórica. En H. Herzer (Org.), Con el corazón mirando al sur. Transformaciones en el sur de la ciudad de Buenos Aires (pp. 97-120). Buenos Aires: Espacio Editorial.

Iparraguire, S. (2001). Quinquela y Victorica. Pintura argentina. Panorama del periodo 18102000. Quinquela y Victorica, 3. 8-19. Buenos Aires: Banco Velox

Iparraguire, S. (2001). La intimidad trascendente. Pintura argentina. Panorama del periodo 1810-2000. Pintores de La Boca I, 19, 10-16. Buenos Aires: Banco Velox

Jackson, P. \& Thrift, N. (1995). Geographies of consumption. En D. Miller (Ed.), Acknowledging consumption: A review of new studies (pp. 204-237). Londres: Routledge.

Lacarrieu, M. (2007). Habitantes de La Boca en Buenos Aires. El conventillo: ¿ৃivienda, recurso o paisaje cultural? Revista d'Etnología de Catalunya, Dossier Antropología Urbana, 31, 44-58.

Lefebvre, H. (1973). El derecho a la ciudad. Barcelona: Península.

Mathivet, Ch. (2010). El derecho a la ciudad: claves para entender la propuesta de crear "otra ciudad posible”. En A. Sugranyes \& Ch. Mathivet (Eds.), Ciudades para tod@s: por el derecho a la ciudad, propuestas y experiencias (pp. 23-28). Santiago de Chile: Habitat International Coalition.

Martin, R. \& Sunley, P. (2003). Deconstructing clusters: Chaotic concept or policy panacea? Journal of Economic Geography, 3(1), 5-35. doi: 10.1093/jeg/3.1.5

Pacheco-Vega, R. (2007). Una crítica al paradigma de desarrollo regional mediante clusters industriales forzados. Estudios Sociológicos, 25(75), 683-707. Disponible en http:// www.redalyc.org/articulo.oa?id=59825303

Slater, D. \& Ariztía, T. (2009). Assembling Asturias: Scaling devices and cultural leverage. En I.Farias \& T. Bender (Eds.), Urban assemblages. How actor-network theory changes urban studies (pp. 91-108). Londres / Nueva York: Routledge.

Tironi, M. (2010). ¿Qué es un cluster? Geografías y prácticas de la escena de música experimental en Santiago, Chile. EURE, 36(109), 161-187. http://dx.doi.org/10.4067/S025071612010000300007

Thomasz, A. (2013). "No lo van a limpiar para nosotros". Algunas reflexiones sobre el cambio urbano en La Boca. Ponencia presentada en el XXIX Congreso de la Asociación Latinoamericana de Sociología (ALAS). Santiago de Chile, 29 de septiembre al 4 de octubre de 2013. Disponible en http://actacientifica.servicioit.cl/biblioteca/gt/GT2/ GT2_ThomaszA.pdf

Thomasz, A. (2014). La estetización, la nivelación y el saneamiento como metáforas del cambio urbano en La Boca. Anuario Antropología Social y Cultural en Uruguay, 12, 93-105. 


\section{Fuentes}

Comisión de Vivienda del Consejo Económico y Social (2013). Diagnóstico sociohabitacional de la Ciudad de Buenos Aires. Informe preliminar. Buenos Aires: Autor.

Espacio Chico Mendes [Blog] (2013). La ciudad: nuestro bien común más preciado. Disponible en http://espaciochicomendes.blogspot.cl/search?updated-max=2013-03-19T10:06:0007:00\&max-results $=50$

Instituto Nacional de Estadística y Censos (INDEC) (2010). Censo de Población, Hogares y Vivienda 2010. Buenos Aires: Autor.

Municipalidad de la Ciudad de Buenos Aires (1988). Programa Recup Boca: Una carta de desarrollo social y urbano del barrio. Buenos Aires: Autor.

onu-Habitat (2004). Carta Mundial por el Derecho a la Ciudad. [Foro Social de las Américas - Quito, julio 2004; Foro Mundial Urbano - Barcelona, octubre 2004; Foro Social Mundial - Porto Alegre, enero 2005; Revisión previa a Barcelona, septiembre 2005]. Disponible en http://www.onuhabitat.org/index.php?option=com_docman\&task= doc_details\&gid=50\&Itemid=3 